\title{
SEGMENTACIÓN DE LOS SENIORS EN FUNCIÓN DE LOS PRODUCTOS QUE COMPRAN POR INTERNET: IMPACTO EN LA INDUSTRIA TURÍSTICA*
}

\author{
Eduard Cristóbal-Fransi \\ Berta Ferrer-Rosell \\ Natalia Daries-Ramon \\ Universidad de Lleida
}

\begin{abstract}
RESUMEN
Los seniors se configuran como un colectivo de especial relevancia para un gran número de industrias. El cambio en el estilo de vida de la población mayor más orientada actualmente al disfrute del tiempo libre que generaciones anteriores y por tanto, más propensa a viajar, beneficia al sector turístico. Hasta ahora, estudios centrados en los seniors han analizado su comportamiento como algo homogéneo en comparación con otras franjas de edad. En esta investigación, con una muestra útil de 2.541 individuos, partimos de la consideración que dicho grupo es heterogéneo, con distintas características y niveles de uso de Internet, y proponemos, mediante una clasificación, tres perfiles de internautas seniors en función de los productos comprados en línea. Encontramos un segmento que utiliza Internet para comprar, sobretodo, productos y servicios turísticos. En las conclusiones se presentan las reflexiones más significativas sobre los segmentos obtenidos y su implicación en la gestión.
\end{abstract}

Palabras clave: segmentación, comportamiento del consumidor, turismo, uso de Internet, comercio electrónico.

Recibido: 20 de abril de 2016

Devuelto para su revisión: 12 de diciembre de 2016

Aceptado: 20 de febrero de 2017

Grupo de Investigación en Turismo, Economía Social y del Conocimiento. Departamento de Administración de Empresas. Universidad de Lleida. C/ Jaume II, 73. Campus de Cappont, 25001 LLEIDA (España). E-mail: ecristobal@aegern.udl.cat, berta.ferrer@aegern.udl.cat,ndaries@aegern.udl.cat

"Agradecimientos: Los autores agradecen a la Generalitat de Catalunya por la acreditación concedida como Grupo Emergente de Investigación GRTESC (2014 SGR 82). A su vez agradecen a la Universidad de Lleida, por la ayuda concedida dentro del marco del Programa de Promoción de la Investigación de la UdL, convocatoria 2014. Los autores agradecen al Dr. Germà Coenders sus comentarios en la parte metodológica.

Financiación: La segunda autora, agradece al Ministerio de Economía y Competitividad la concesión del proyecto MTM2015-65016-C2-1-R "COmpositional Data Analysis and RElated meThOdS (CODA-RETOS)" 


\title{
Segmentation of seniors based on products bought on the Internet: impact on tourism industry
}

\begin{abstract}
Seniors constitute a special relevant group of consumers for a quite number of industries. Changes in old-year population's lifestyle, which is more oriented to leisure and enjoying their free time than past generations benefit tourism sector. Until now studies about seniors have analyzed their behavior as something homogeneous compared to other age groups. In this article, with a sample of 2541 individuals, we consider senior group as heterogeneous, showing different characteristics and different levels of the use of Internet. We propose, by means of a classification, three profiles of senior surfers based on products and services bought through the Internet. In the conclusions we present the main significant thoughts and management implications for the segments found.
\end{abstract}

Keywords: segmentation, consumer behavior, tourism, Internet use, e-commerce.

\section{INTRODUCCIÓN}

La progresiva consolidación de las tecnologías de la información y la comunicación, en especial el uso tanto del ordenador personal para acceder a la Red, como de una gran diversidad de terminales, ha permitido ir avanzando en el conocimiento de las motivaciones, así como de los temores, de los internautas. El hecho de que ya sean millones los usuarios de Internet, así como respetable el volumen de transacciones comerciales que se llevan a cabo en el entorno virtual, exige conocer a fondo las actitudes de tales usuarios frente al medio y como este ha modificado su comportamiento de compra. Si nos centramos en el sector turístico, Internet ha mejorado la experiencia de los turistas en sus viajes mediante la ampliación de las fuentes de información y las posibilidades de adquirir el producto o servicio turístico (Cristobal-Fransi et al., 2013). Comprender el comportamiento actual y futuro de los turistas con respecto a los recursos en línea podría tener un impacto en cómo los destinos y las empresas crean, desarrollan y distribuyen sus servicios y productos (Vigolo y Confente, 2013; Moutinho et al., 2011).

Tal como se señala en los trabajos de Berné et al. (2015) y Ramos et al. (2015), el uso de las TICs tiene una especial incidencia en la innovación en el sector turístico, dando lugar a la investigación y desarrollo de nuevos productos. Por otro lado, tenemos que tener en cuenta que la innovación no sólo se consigue incorporando tecnología, sino gestionándola correctamente. En este sentido, la aplicación del comercio electrónico al turismo permite la reducción de barreras geográficas, alcanzando por tanto una escala internacional y accediendo a más clientes (Ortega et al., 2012). A nivel de comportamiento de los usuarios de servicios turísticos, los hábitos de compra y de consumo de los individuos también se han visto influenciados por las nuevas tecnologías (Kim y Fesenmaier, 2008; González-Rodrigo et al., 2010). De hecho, Internet permite que el consumidor sea cada vez más exigente y que esté mejor informado, y por ello asume cada vez más la gestión de sus viajes y desplazamientos (Chen y Law, 2016). 
De esta manera, no todos los usuarios tienen la misma frecuencia de acceso a la Red, ni buscan y compran los mismos bienes o servicios una vez instalados en ella. No obstante, la clasificación de los internautas en grupos suficientemente homogéneos en cuanto a perfil personal, socioeconómico y formas de uso de la Red, no es tarea fácil (Cristobal-Fransi et al., 2015). Si bien, el comportamiento en línea de los turistas ha sido ampliamente estudiado en lo que respecta a la parte más joven de la población (Nusair et al., 2012), se ha trabajado menos en el segmento de turistas de edad avanzada.

La presente investigación tiene como objetivo principal analizar y tipificar el comportamiento de los seniors a la hora de adquirir productos y servicios a través de internet, y más específicamente, analizar el turista senior que compra especialmente productos y servicios turísticos. La segmentación de mercados basada en los productos o servicios comprados a través de internet puede ser utilizado para clasificar e identificar a los diferentes grupos de clientes y para proporcionar un claro entendimiento de cada segmento, tanto de sus motivos, como de sus características y necesidades (Swinyard y Smith, 2003). Esta información puede permitir a las empresas conseguir una clara ventaja estratégica sobre sus competidores ya que les facilitará la identificación de las actitudes y necesidades de los diferentes segmentos y de esta manera convertir estas oportunidades estratégicas en planes de acción efectivos (Dibb et al., 2002).

La dirección de la empresa puede utilizar este enfoque de segmentación basado en los productos comprados en línea, para la realización de una óptima clasificación de sus clientes y de esta manera desarrollar acciones comerciales más eficientes. El presente artículo está dividido en las siguientes secciones. En la primera sección se realiza una revisión de la literatura sobre la importancia que representan los seniors para la industria turística y la segmentación de mercados en un entorno virtual. A continuación en la sección de metodología, se detallan los datos y su análisis. En el siguiente apartado, se exponen los principales resultados, describiendo cada uno de los segmentos obtenidos y posicionándolos. Finalmente se muestran las conclusiones junto con las implicaciones tanto académicas como de gestión que este estudio aporta, las limitaciones y las futuras líneas de investigación.

\section{ENVEJECIMIENTO DE LA POBLACIÓN E IMPORTANCIA PARA EL SECTOR TURÍSTICO}

Según datos del Instituto Nacional de Estadística en 35 años el $40 \%$ de la población española estará por encima de los 59 años, prácticamente el doble de 2015, que se sitúa en el 18,5\% (Instituto Nacional de Estadística, 2015a). Si nos centramos en el turista senior, la Organización Mundial de Turismo calcula que para el año 2050 la población de 60 años en adelante llegará a representar más de dos mil millones de viajes internacionales, frente a los 593 millones que representó en 1999 (Patterson, 2006). En España, en el año 2015, según los datos de la Encuesta de Turismo de Residentes, el colectivo de 65 años o más representaba el 11,9\% del total de viajes y la duración media de pernoctaciones más alta con 4,8 (Instituto Nacional de Estadística, 2015b).

El proceso de envejecimiento de la población va a provocar que el turismo senior sea considerado como uno de los segmentos de mayor crecimiento y más importantes dentro 
de la industria turística (Losada et al., 2015; Glover y Prideaux, 2009) ya que actualmente gozan de una mejor salud física y mental y con muchas ganas de disfrutar de una vida plena después del periodo activo (Alén et al., 2010). Este colectivo conforma el "motor del crecimiento" en turismo (Schröder y Widmann, 2007). Además los seniors disponen de todo el tiempo para viajar sin horarios ni calendarios estipulados (Fleischer y Pizam, 2002; Lohmann y Danielsson, 2001), pudiendo realizar viajes de mayor duración y de forma más frecuente que la población joven (Schröder y Widmann, 2007; Oppermann, 1995). Siguiendo esta línea, son varios los autores como Chen y Shoemaker (2014), Mahadevan (2014), Chu y Chu (2013), Cooper et al. (2007), Glover y Prideaux (2009), que apuntan a las generaciones envejecidas del baby boom como uno de los mercados más relevantes en el ámbito turístico. Se estima que en los próximos cinco años los seniors prevalecerán demográficamente, económicamente y culturalmente (Morgan et al., 2015; Chen et al., 2013; Wang et al., 2013; Schröder y Widmann, 2007; Tréguer y Ségati, 2005), y que al menos un 10\% de los gastos de marketing estarán dirigidos a este target (Lambert-Pandraud et al., 2005).

El estudio de este segmento se revela de gran importancia para la industria turística por su poder adquisitivo (Kazeminia et al., 2015; Kuo y Lu, 2013; Van Den Berg et al., 2011; Dann, 2007) y el tiempo libre disponible (Fleischer y Pizam, 2002). Este tiempo libre frecuentemente ha sido ocupado en actividades turísticas (Losada et al., 2015). Por otro lado y según Thébault et al. (2013), a pesar de que haya una gran disparidad en el nivel de ingresos de las personas mayores, en los países industrializados tienen un poder adquisitivo que está por encima de la media. Esto representa una base de clientes potenciales para la industria turística que no se puede obviar. Lohmann y Danielsson (2001) ponen de manifiesto que el comportamiento turístico de los seniors actuales está relacionado con el que manifestaban estas personas hace 15 años más que con los seniors de hace unos años. Los seniors actuales son gente más culta, exigente y con unas preferencias diferentes, que han viajado más durante su juventud y que probablemente seguirá haciéndolo (Jang y Wu, 2006). Por otro lado, también se tiene que considerar que los seniors de las futuras décadas son gente mucho más formada y avanzada a nivel tecnológico, familiarizadas con los entornos virtuales y acostumbradas a realizar compras on-line a diferencia de las generaciones anteriores (Nielsen, 2014; Richter, 2013; Jang y Ham, 2009).

\section{REVISIÓN DE LA LITERATURA SOBRE EL EFECTO DE INTERNET EN EL COMPORTAMIENTO DE COMPRA DE PRODUCTOS TURÍSTICOS POR PARTE DEL TURISTA SENIOR}

Siguiendo los trabajos de Chen et al. (2013), las personas mayores se pueden clasificar en seniors potenciales (50-64 años) y seniors (65 años y más). El estudio de los seniors potenciales es relevante debido a que su comportamiento de consumo podría utilizarse en el futuro para predecir las pautas de consumo del turismo senior y para desarrollar y adaptar nuevos productos turísticos para este mercado (Jang y Wu, 2006).

La importancia del segmento de turistas de más edad ha sido ampliamente reconocida tanto por profesionales como por los investigadores del sector turístico (Hunter-Jones y Blackburn, 2007). La literatura se ha centrado principalmente en (ver Tabla I): a) las motivaciones de viaje de los turistas senior (Ward, 2014, Le Serre et al., 2013; Cheng y 
Wu, 2009; Boksberger y Laesser, 2009); b) los factores psicológicos (Jang et al., 2009; Jang y Wu, 2006); c) las características de la experiencia (Batra, 2009; Hunter-Jones y Blackburn, 2007); d) las necesidades del servicio (Chen et al., 2013; Wang et al,. 2013) y las características sociodemográficas (Pesonen et al., 2015; Peral et al., 2013; Jang y Ham, 2009). Sin embargo, poco se ha investigado sobre la influencia de Internet y el tipo de producto adquirido en el mercado senior (Vigolo y Confente, 2013). De hecho, la mayoría de los estudios publicados sobre el comportamiento de compra en línea se centra en los consumidores jóvenes, la llamada 'Generación Y” (Nusair et al., 2012).

En definitiva para llevar a cabo estrategias de marketing efectivas, es importante para las empresas turísticas entender las causas de las intenciones de compra en línea de los usuarios. Estudios previos sobre los determinantes de la intención de compra en línea se han centrado en las percepciones y actitudes de los clientes, tales como la percepción de riesgo (Zheng et al., 2012), la competitividad de precios (Degeratu et al., 2000), la facilidad de uso o aspectos de diseño (Wen, 2012); así como el comportamiento previo del turista, como puede ser la búsqueda de información o el comportamiento de compra anterior. Trabajos como los realizados por Alén et al. (2014) y Losada et al. (2016) estudian la duración y frecuencia de los viajes de los seniors españoles, llegando a la conclusión que el género, situación económica percibida y disponibilidad se revelan como unos importantes determinantes a la hora de planificar los viajes de la tercera edad en España.

Debido a la complejidad de considerar todas estas variables, esta investigación tiene la intención de centrarse en la experiencia de compra en línea de los usuarios seniors en vez de las percepciones hacia un entorno en línea. Esto es particularmente relevante en España, donde se calcula que hacia 2023 habrá 19,7 millones de personas mayores de 64 años en España. Un millón y medio más respecto al año 2016 (Instituto Nacional de Estadística, 2016). Según datos del Centro Superior de Investigaciones Científicas, es cierto que se percibe una cierta brecha digital entre los mayores y el resto de la población, ya que a partir de los 55 años se observa un notable descenso en los porcentajes de personas que utilizan Internet, pero cada vez menos. En 2007, seis mayores de 65 años de cada 100 utilizaban Internet (en el último trimestre). En 2015, esta cifra alcanza los 31. Este aumento ha sido más considerable en las mujeres (Abellán y Pujol, 2016). Por otro lado, y según un estudio del Observatorio Nacional de las Telecomunicaciones y de la Sociedad de la Información (2015b), en nuestro país el 22,8\% de la población mayor de 65 accede a Internet con una frecuencia semanal.

Un primer paso hacia la comprensión de la intención de compra en línea de los usuarios de más edad es explorar la tipología de producto que adquiere. Por lo tanto, la investigación de variables actitudinales más específicas está fuera del alcance de este estudio.

Los resultados revelan que, más allá de la renta y el tiempo disponible, la participación en viajes por parte de este segmento va a estar explicada por una serie de variables relacionadas con la edad interna/percibida del individuo, que es aquella que hace referencia a la etapa del ciclo de vida en la que se encuentra; el nivel sociocultural, que origina las diferencias entre las distintas cohortes generacionales, y ciertas variables subjetivas que suponen las principales barreras para el viaje de los senior y que denominamos factores auto-percibidos. Se extraen, además, una serie de implicaciones de gran relevancia para el sector turístico. 


\section{Tabla I \\ PRINCIPALES ESTUDIOS REALIZADOS SOBRE EL TURISTA SENIOR}

\begin{tabular}{|c|c|c|c|c|}
\hline Autor (es) & Muestra & $\begin{array}{l}\text { Método de } \\
\text { análisis }\end{array}$ & $\begin{array}{c}\text { Variables } \\
\text { significativas }\end{array}$ & Principales resultados \\
\hline $\begin{array}{l}\text { Losada, Alén, } \\
\text { Domínguez } \\
\text { y Nicolau } \\
\text { (2016) }\end{array}$ & $\begin{array}{l}\text { Mayores de } 55 \\
\text { (España) }\end{array}$ & $\begin{array}{l}\text { Modelo } \\
\text { Binomial } \\
\text { negativa }\end{array}$ & $\begin{array}{l}\text { - Género, status } \\
\text { económico percibido y } \\
\text { tiempo disponible }\end{array}$ & $\begin{array}{l}\text { La frecuencia de viajar } \\
\text { depende de: variables de } \\
\text { género, autopercepción } \\
\text { económica y autopercepción } \\
\text { de tiempo disponible }\end{array}$ \\
\hline $\begin{array}{l}\text { Kim, Lee y } \\
\text { Bonn (2016) }\end{array}$ & $\begin{array}{l}\text { Usuarios de } \\
\text { redes sociales } \\
\text { mayores de } 50 \\
\text { (Korea) }\end{array}$ & PLS-SEM & $\begin{array}{l}\text { - Capital social y } \\
\text { altruismo }\end{array}$ & $\begin{array}{l}\text { Se muestran efectos } \\
\text { positivos entre el capital } \\
\text { social y el altruismo con } \\
\text { el vínculo común y la } \\
\text { identidad, que llevan a la } \\
\text { revisita. }\end{array}$ \\
\hline $\begin{array}{l}\text { Pesonen, } \\
\text { Komppula } \\
\text { y Riihinen } \\
(2015)\end{array}$ & $\begin{array}{l}\text { Mayores } \\
\text { de } 60 \text { años } \\
\text { (Finlandia) }\end{array}$ & $\begin{array}{l}\text { Análisis } \\
\text { cualitativo }\end{array}$ & $\begin{array}{l}\text { - Variables } \\
\text { sociodemográficas }\end{array}$ & $\begin{array}{l}\text { Tres segmentos basados en } \\
\text { el uso de servicios online } \\
\text { de viajes: aventureros, } \\
\text { buscadores meticulosos y } \\
\text { observadores torpes }\end{array}$ \\
\hline $\begin{array}{l}\text { Losada, Alén } \\
\text { y Domínguez } \\
(2015)\end{array}$ & $\begin{array}{l}\text { Mayores de } 55 \\
\text { (España) }\end{array}$ & $\begin{array}{l}\text { Regresión } \\
\text { logística } \\
\text { binaria }\end{array}$ & $\begin{array}{l}\text { - Renta y tiempo } \\
\text { disponible, edad } \\
\text { interna del individuo; } \\
\text { nivel sociocultural; } \\
\text { factores auto- } \\
\text { percibidos }\end{array}$ & $\begin{array}{l}\text { Viajar depende de la } \\
\text { edad interna/percibida } \\
\text { del individuo, el nivel } \\
\text { sociocultural, y los factores } \\
\text { auto-percibidos }\end{array}$ \\
\hline Ward (2014) & $\begin{array}{l}\text { Mayores de } 50 \\
\text { (Irlanda) }\end{array}$ & $\begin{array}{l}\text { Técnicas } \\
\text { multivariables } \\
\text { y análisis } \\
\text { cluster }\end{array}$ & $\begin{array}{l}\text { - Variables } \\
\text { motivacionales push, } \\
\text { pull, preferencias y } \\
\text { restricciones turísticas }\end{array}$ & $\begin{array}{l}\text { Se extraen cuatro segmentos: } \\
\text { viajeros entusiastas, } \\
\text { exploradores culturales, } \\
\text { soñadores y viajeros } \\
\text { espirituales }\end{array}$ \\
\hline $\begin{array}{l}\text { Peral, Gaitán } \\
\text { y Ramón } \\
(2013)\end{array}$ & $\begin{array}{l}\text { Estudiantes } \\
\text { de aula senior } \\
\text { mayores de } 60 \\
\text { (España) }\end{array}$ & $\begin{array}{l}\text { Pruebas no } \\
\text { paramétricas }\end{array}$ & $\begin{array}{l}\text { - Variables } \\
\text { sociodemográficas }\end{array}$ & $\begin{array}{l}\text { El uso de aplicaciones } \\
\text { dependen de: la edad, el } \\
\text { sexo, el nivel de estudios } \\
\text { alcanzados y la actividad } \\
\text { laboral desarrollada en el } \\
\text { pasado. }\end{array}$ \\
\hline $\begin{array}{l}\text { Peral, } \\
\text { Rodríguez- } \\
\text { Bobada, } \\
\text { Sánchez y } \\
\text { Villarejo } \\
\text { (2011) }\end{array}$ & $\begin{array}{l}\text { Compradores } \\
\text { de productos } \\
\text { turísticos en } \\
\text { línea mayores } \\
\text { de } 55 \text { años } \\
\text { (España) }\end{array}$ & $\begin{array}{l}\text { Análisis } \\
\text { Conjunto }\end{array}$ & $\begin{array}{l}\text { - Variables } \\
\text { sociodemográficas } \\
\text { - Experiencia de } \\
\text { compra }\end{array}$ & $\begin{array}{l}\text { - Se extraen dos segmentos } \\
\text { diferenciados por su } \\
\text { sensibilidad al precio, } \\
\text { la existencia de gastos } \\
\text { de envío y la existencia } \\
\text { de políticas de garantía } \\
\text { y devolución de los } \\
\text { productos. }\end{array}$ \\
\hline
\end{tabular}




\begin{tabular}{|c|c|c|c|c|}
\hline $\begin{array}{l}\text { Chen y Wu } \\
(2009)\end{array}$ & $\begin{array}{l}\text { Mayores } \\
\text { de } 50 \text { años } \\
\text { en adelante } \\
\text { (Taiwan) }\end{array}$ & $\begin{array}{l}\text { Regresión } \\
\text { logística }\end{array}$ & $\begin{array}{l}\text { - Motivación, barreras } \\
\text { personales, edad, } \\
\text { estado civil, situación } \\
\text { laboral y procedencia } \\
\text { de la renta }\end{array}$ & $\begin{array}{l}\text { Viajar al extranjero depende } \\
\text { de la edad, ingresos, } \\
\text { la situación laboral, } \\
\text { restricciones personales, o la } \\
\text { búsqueda de relax, novedad } \\
\text { o socialización. }\end{array}$ \\
\hline $\begin{array}{l}\text { Jang y Ham } \\
(2009)\end{array}$ & $\begin{array}{l}\text { Mayores } \\
\text { de } 50 \text { años } \\
\text { en adelante } \\
\text { (Estados } \\
\text { Unidos) } \\
\end{array}$ & $\begin{array}{l}\text { Análisis } \\
\text { probit }\end{array}$ & $\begin{array}{l}\text { - Edad, edad, estado } \\
\text { civil, lugar de origen, } \\
\text { tamaño del hogar, } \\
\text { nivel educativo, región } \\
\text { y renta del hogar }\end{array}$ & $\begin{array}{l}\text { Viajar depende de la edad, el } \\
\text { estado civil, la educación y } \\
\text { los ingresos }\end{array}$ \\
\hline $\begin{array}{l}\text { González, } \\
\text { Rodríguez, } \\
\text { Miranda y } \\
\text { Cervantes } \\
(2009)\end{array}$ & $\begin{array}{l}\text { Turistas, } \\
\text { mayores de } 55 \\
\text { años (España) }\end{array}$ & $\begin{array}{l}\text { Análisis de } \\
\text { componentes } \\
\text { principales. } \\
\text { Clúster. }\end{array}$ & $\begin{array}{l}\text { - } \text { Edad cognitiva } \\
\text { - } \text { Motivaciones } \\
\text { - } \text { Características } \\
\text { sociodemográficas }\end{array}$ & $\begin{array}{l}\text { - En función de la edad } \\
\text { cognitiva se extraen dos } \\
\text { segmentos: los activos y los } \\
\text { pasivos estables }\end{array}$ \\
\hline $\begin{array}{l}\text { Boksberger } \\
\text { y Laesser } \\
(2009)\end{array}$ & $\begin{array}{l}\text { Turistas, } \\
\text { mayores de } 55 \\
\text { años (Suiza) }\end{array}$ & $\begin{array}{l}\text { Clúster con } \\
\text { análisis } \\
\text { K-medias }\end{array}$ & $\begin{array}{l}\text { - Motivaciones de } \\
\text { viaje }\end{array}$ & $\begin{array}{l}\text { Extraen tres segmentos: } \\
\text { Bon Vivants honrosos, } \\
\text { exploradores canosos y } \\
\text { viajeros retro. }\end{array}$ \\
\hline $\begin{array}{l}\text { Nyaupane, } \\
\text { McCabe y } \\
\text { Andereck } \\
(2008)\end{array}$ & $\begin{array}{l}\text { Suscriptores } \\
\text { de revistas de } \\
\text { viajes (Estados } \\
\text { Unidos) }\end{array}$ & $\begin{array}{l}\text { Análisis de } \\
\text { regresión } \\
\text { logística }\end{array}$ & $\begin{array}{l}\text { - Edad, estado civil y } \\
\text { renta }\end{array}$ & $\begin{array}{l}\text { Se muestra el papel de la } \\
\text { edad y el nivel de ingresos } \\
\text { como factores restrictivos. }\end{array}$ \\
\hline $\begin{array}{l}\text { Jang y Wu } \\
(2006)\end{array}$ & $\begin{array}{l}\text { Mayores } \\
\text { de } 60 \text { años } \\
\text { en adelante } \\
\text { (Taiwan) }\end{array}$ & $\begin{array}{l}\text { Regresión } \\
\text { logística }\end{array}$ & $\begin{array}{l}\text { - Edad y estatus } \\
\text { económico } \\
\text { autopercibido }\end{array}$ & $\begin{array}{l}\text { Se extraen cinco factores } \\
\text { push: mejora del ego, } \\
\text { autoestima, búsqueda de } \\
\text { conocimiento, relajación y } \\
\text { socialización. Y tres factores } \\
\text { pull: limpieza y seguridad, } \\
\text { instalaciones, eventos y } \\
\text { coste y patrimonio histórico } \\
\text { y natural. }\end{array}$ \\
\hline $\begin{array}{l}\text { Shim, Gehrt y } \\
\text { Siek (2005) }\end{array}$ & $\begin{array}{l}\text { Mayores } \\
\text { de } 55 \text { años } \\
\text { en adelante } \\
\text { (Estados } \\
\text { Unidos) }\end{array}$ & $\begin{array}{l}\text { Análisis de } \\
\text { regresión } \\
\text { múltiple }\end{array}$ & $\begin{array}{l}\text { - Experiencia de viaje } \\
\text { previa }\end{array}$ & $\begin{array}{l}\text { Agentes socializadores, } \\
\text { variables sociales } \\
\text { estructurales y los } \\
\text { componentes actitudinales } \\
\text { afectan al comportamiento } \\
\text { de viajes pasados y las } \\
\text { intenciones futuras de viaje. }\end{array}$ \\
\hline $\begin{array}{l}\text { Fleischer y } \\
\text { Pizam (2002) }\end{array}$ & $\begin{array}{l}\text { Mayores } \\
\text { de } 55 \text { años } \\
\text { en adelante } \\
\text { (Israel) }\end{array}$ & $\begin{array}{l}\text { Análisis } \\
\text { probit }\end{array}$ & - Salud y renta & $\begin{array}{l}\text { La motivación de viajar } \\
\text { están en función del nivel } \\
\text { de ingresos y la salud, pero } \\
\text { la duración del viaje cambia } \\
\text { con la edad }\end{array}$ \\
\hline $\begin{array}{l}\text { Zimmer, } \\
\text { Brayley y } \\
\text { Searle (1995) }\end{array}$ & $\begin{array}{l}\text { Mayores } \\
\text { de } 65 \text { años } \\
\text { en adelante } \\
\text { (Canadá) }\end{array}$ & $\begin{array}{l}\text { Análisis } \\
\text { discriminante }\end{array}$ & $\begin{array}{l}\text { - Estado civil, propiedad } \\
\text { de la vivienda, renta } \\
\text { del hogar, edad, nivel } \\
\text { educativo, estado de } \\
\text { salud y características } \\
\text { actitudinales }\end{array}$ & $\begin{array}{l}\text { Factores como los ingresos, } \\
\text { educación, lugar de } \\
\text { residencia, la disposición } \\
\text { a gastar dinero en ocio y el } \\
\text { estado de salud influyen en } \\
\text { la elección del destino }\end{array}$ \\
\hline
\end{tabular}

Fuente: elaboración propia. 


\section{METODOLOGÍA}

Los datos utilizados para la realización de este trabajo provienen de la encuesta sobre Equipamiento y Uso de Tecnologías de la Información y Comunicación en los hogares de 2015 (TIC-H'15) del Instituto Nacional de Estadística, que proporciona información sobre el uso de las tecnologías de la información y la comunicación de la población española. Según el informe metodológico de la TIC-H'15 (Instituto Nacional de Estadística, 2015c) la encuesta se realizó a 15.507 viviendas del territorio español, durante los meses de enero a mayo de 2015, tanto en Computer-Assisted Personal Interviewing como en ComputerAssisted Telephone Interviewing.

Para el análisis, que a diferencia de buena parte de los trabajos incluidos en la Tabla 1 , éste es de carácter clasificatorio, se han seleccionado aquellos individuos de 54 años o mayores (seniors y seniors potenciales), y aquellos que han declarado haber utilizado Internet en los últimos 3 meses. En un primer momento, se hace una segmentación $a$ priori (Dolnicar, 2004), seleccionando aquellos usuarios que compran y aquellos que no compran productos o servicios a través de internet. En segundo lugar, se hace una clasificación data-driven (Dolnicar, 2004) para segmentar aquellos individuos que sí compran a través de Internet. La muestra consta de 2.541 individuos, de los cuales 868 , han comprado productos y/o servicios a través de Internet, y el resto no.

Con el fin de reducir la información y disponer de variables numéricas para realizar la segmentación mediante el análisis clúster, se procede, en primer lugar, a realizar un análisis de correspondencias múltiples de las variables binarias referentes a la compra de productos o servicios comprados a través de Internet. Éstas variables corresponden a los productos o servicios que se enumeraban en la pregunta 42 del cuestionario TIC-H 2015, en la que se le pedía al encuestado que dijera si compró o no (o encargó) a través de internet alguno o algunos de los productos o servicios listados. La pregunta incluye 16 productos o servicios y se han utilizado todos excepto "medicamentos" y "otros productos y servicios" por su bajo número de usuarios que lo compraron y por su inconcreción, respectivamente. Por otro lado, algunos productos o servicios similares se han juntado en una sola variable (por ejemplo, equipo informático, equipamiento electrónico y juegos y software de ordenador).

El análisis de correspondencias múltiples permite tratar variables cualitativas o categóricas a fin de reducir y resumir un conjunto mixto de variables, y plasmarlas en un número reducido de dimensiones (Le Roux y Rouanet, 2010; Hoffman et al., 1994). La Tabla 2 muestra la inercia explicada por cada dimensión y las inercias corregidas según Benzécri (1979). Las inercias corregidas conducen a seleccionar dos ejes (las dos primeras dimensiones).

Tabla 2

INERCIA EXPLICADA POR CADA DIMENSIÓN

\begin{tabular}{|c|c|c|}
\hline Dimensión & Inercia & Inercia corregida \\
\hline Dimensión 1 & 0,222 & 0,02087 \\
\hline Dimensión 2 & 0,116 & 0,00077 \\
\hline Dimensión 3 & 0,092 & 0,00000 \\
\hline
\end{tabular}

Fuente: elaboración propia. 
Dichas dimensiones se utilizan posteriormente como base de segmentación en el análisis clúster, que en un tercer momento, se relacionan con variables sociodemográficas y de comportamiento para, precisamente, perfilar las características de cada uno de los segmentos obtenidos. Las variables utilizadas como ilustrativas son por un lado, edad, género, nivel de estudios, ingresos mensuales y situación laboral; y por otro lado, gasto realizado en compras por internet, frecuencia de compra, perfil de compra, variables relativas al uso de otros dispositivos electrónicos, frecuencia de uso de internet o si han experimentado problemas de seguridad.

La Tabla 3, por su lado, muestra las contribuciones de las variables activas a las dimensiones extraídas, y se observa que la segunda dimensión incluye la compra de productos o servicios relacionados con el turismo.

Tabla 3

FRECUENCIAS Y CONTRIBUCIONES DE LAS VARIABLES ACTIVAS A LAS DIMENSIONES DEL ANÁLISIS DE CORRESPONDENCIAS MÚLTIPLES (NOMBRE DE LAS VARIABLE)

\begin{tabular}{|c|c|c|c|c|}
\hline Variables & & Frec. & Dim. 1 & Dim. 2 \\
\hline \multirow{3}{*}{$\begin{array}{l}\text { Productos de alimentación y de consumo no } \\
\text { duraderos (super) }\end{array}$} & \begin{tabular}{|l|} 
No compra \\
\end{tabular} & 732 & 0,001 & 0,003 \\
\hline & Sí compra & 136 & 0,006 & 0,016 \\
\hline & Total activo & & 0,008 & 0,019 \\
\hline \multirow{3}{*}{ Bienes para el hogar (hog_dura) } & No compra & 656 & 0,011 & 0,031 \\
\hline & Sí compra & 212 & 0,035 & 0,094 \\
\hline & \begin{tabular}{|l|} 
Total activo \\
\end{tabular} & & 0,046 & 0,125 \\
\hline \multirow{3}{*}{$\begin{array}{l}\text { Películas, música, libros, revistas, periódicos } \\
\text { (libros) }\end{array}$} & No compra & 626 & 0,038 & 0,002 \\
\hline & Sí compra & 242 & 0,098 & 0,006 \\
\hline & \begin{tabular}{|l|} 
Total activo \\
\end{tabular} & & 0,137 & 0,008 \\
\hline \multirow[t]{3}{*}{ Material formativo (formativo) } & No compra & 807 & 0,007 & 0,005 \\
\hline & Sí compra & 61 & 0,095 & 0,061 \\
\hline & Total activo & & 0,103 & 0,65 \\
\hline \multirow[t]{3}{*}{ Material deportivo, ropa (deport_ropa) } & No compra & 604 & 0,006 & 0,023 \\
\hline & Sí compra & 264 & 0,015 & 0,053 \\
\hline & Total activo & & 0,021 & 0,077 \\
\hline \multirow{3}{*}{$\begin{array}{l}\text { Juegos de ordenador o videoconsolas, } \\
\text { software de ordenador y actualizaciones; } \\
\text { equipo informático; equipamiento electrónico } \\
\text { (electrónica) }\end{array}$} & No compra & 601 & 0,023 & 0,026 \\
\hline & Sí compra & 267 & 0,051 & 0,059 \\
\hline & Total activo & & 0,073 & 0,085 \\
\hline \multirow{3}{*}{$\begin{array}{l}\text { Servicios de } \\
\text { (telecomunicaciones) }\end{array}$} & No compra & 774 & 0,012 & 0,007 \\
\hline & Sí compra & 94 & 0,102 & 0,061 \\
\hline & Total activo & & 0,114 & 0,68 \\
\hline
\end{tabular}




\begin{tabular}{|l|l|l|l|l|}
\hline Variables & & Frec. & Dim. 1 & Dim. 2 \\
\hline \multirow{2}{*}{$\begin{array}{l}\text { Acciones, pólizas de seguros u otros servicios } \\
\text { financieros (financieros) }\end{array}$} & No compra & 803 & 0,005 & 0,002 \\
\cline { 2 - 5 } & Sí compra & 65 & 0,060 & 0,030 \\
\cline { 2 - 5 } & Total activo & & 0,065 & 0,032 \\
\hline \multirow{4}{*}{ Alojamiento de vacaciones (alojamiento) } & No compra & 385 & 0,090 & 0,110 \\
\cline { 2 - 5 } & Sí compra & 483 & 0,072 & 0,88 \\
\cline { 2 - 5 } & Total activo & & 0,162 & 0,197 \\
\hline \multirow{4}{*}{ Otros servicios de viajes (otros_viajes) } & No compra & 411 & 0,069 & 0,139 \\
\cline { 2 - 5 } & Sí compra & 457 & 0,062 & 0,125 \\
\cline { 2 - 5 } & Total activo & & 0,130 & 0,264 \\
\hline \multirow{2}{*}{ Entradas para espectáculos (espectáculos) } & No compra & 552 & 0,052 & 0,021 \\
\cline { 2 - 5 } & Sí compra & 316 & 0,090 & 0,037 \\
\cline { 2 - 5 } & Total activo & & 0,142 & 0,058 \\
\hline
\end{tabular}

Fuente: elaboración propia.

Para el análisis clúster se utiliza el método de Ward, ya que tiende a minimizar la suma de cuadrados dentro de los grupos y se considera el más apropiado cuando la distancia euclídea al cuadrado tiene sentido para los datos, que es el caso de los ejes del análisis de correspondencias múltiples (Everitt et al., 2001). En la Tabla 4, se muestran las frecuencias y las coordenadas de la solución de tres clústers, que es la situación seleccionada. El porcentaje de varianza de los ejes explicada por la clasificación es la media de los valores Eta al cuadrado de las dos dimensiones extraídas. En el caso de la solución de tres clústers, ésta es de $61,85 \%$, en el caso de la solución de cuatro clústers es de $71,25 \%$ y en el caso de la solución de cinco clústers es de 78,35\%. Como es obvio, a medida que se aumenta el número de clústers, aumenta también el porcentaje de varianza explicada. De todas formas, la interpretabilidad de los segmentos en referencia al objetivo del estudio, es clave para decidir el número de segmentos a caracterizar, además del hecho de que incrementar el número de segmentos aporta confusión.

Tabla 4

FRECUENCIA Y COORDENADAS DE LOS CLÚSTERS EN CADA UNA DE LAS DIMENSIONES

\begin{tabular}{|c|c|c|c|c|}
\hline Clúster & Frecuencia & $\boldsymbol{\%}$ & $\begin{array}{c}\text { Coordenadas } \\
\text { Dimensión 1 }\end{array}$ & $\begin{array}{c}\text { Coordenadas } \\
\text { Dimensión 2 }\end{array}$ \\
\hline 1 & 449 & 51,7 & $-0,639$ & $-0,569$ \\
\hline 2 & 64 & 7,4 & 2,266 & $-1,033$ \\
\hline 3 & 355 & 40,9 & 0,399 & 0,906 \\
\hline Total & 868 & \multicolumn{3}{|c}{} \\
\hline
\end{tabular}

Fuente: elaboración propia. 
La Figura 1 muestra cómo quedan representadas las categorías de las variables de compra por Internet de productos o servicios según las dos dimensiones extraídas del análisis de correspondencias múltiples. También se muestran los centros de los clústers (segmentos) obtenidos. Interpretando el gráfico por zonas, se observa que en la zona central y en la parte positiva de la segunda dimensión se concentran los productos turísticos (alojamiento y otros servicios de viajes), juntamente con la compra de entradas para espectáculos. Por otro lado, en la zona sur-este, parte positiva y alta de la primera dimensión y negativa de la dimensión dos, se concentran aquellos productos y servicios que son menos comprados a través de Internet (frecuencias más pequeñas), como son los productos y servicios financieros, las acciones y pólizas de seguro, conjuntamente con material formativo y servicios de telecomunicaciones. Es posible que los individuos que compran estos productos, también utilicen Internet para comprar el resto de productos y servicios. En la zona central del gráfico se encuentran los productos y servicios de carácter genérico (deporte y ropa; productos de alimentación y no duraderos; películas, libros, revistas; equipamiento electrónico y bienes duraderos para el hogar). En la zona negativa de ambas dimensiones se encuentran aquellos individuos que no compran servicios turísticos, y finalmente, en la zona negativa de la dimensión 1 y la positiva de la dimensión 2, se aglutinan las categorías de "no compra" de los demás productos y servicios.

\section{Figura 1}

\section{POSICIONAMIENTO DE LOS SEGMENTOS}

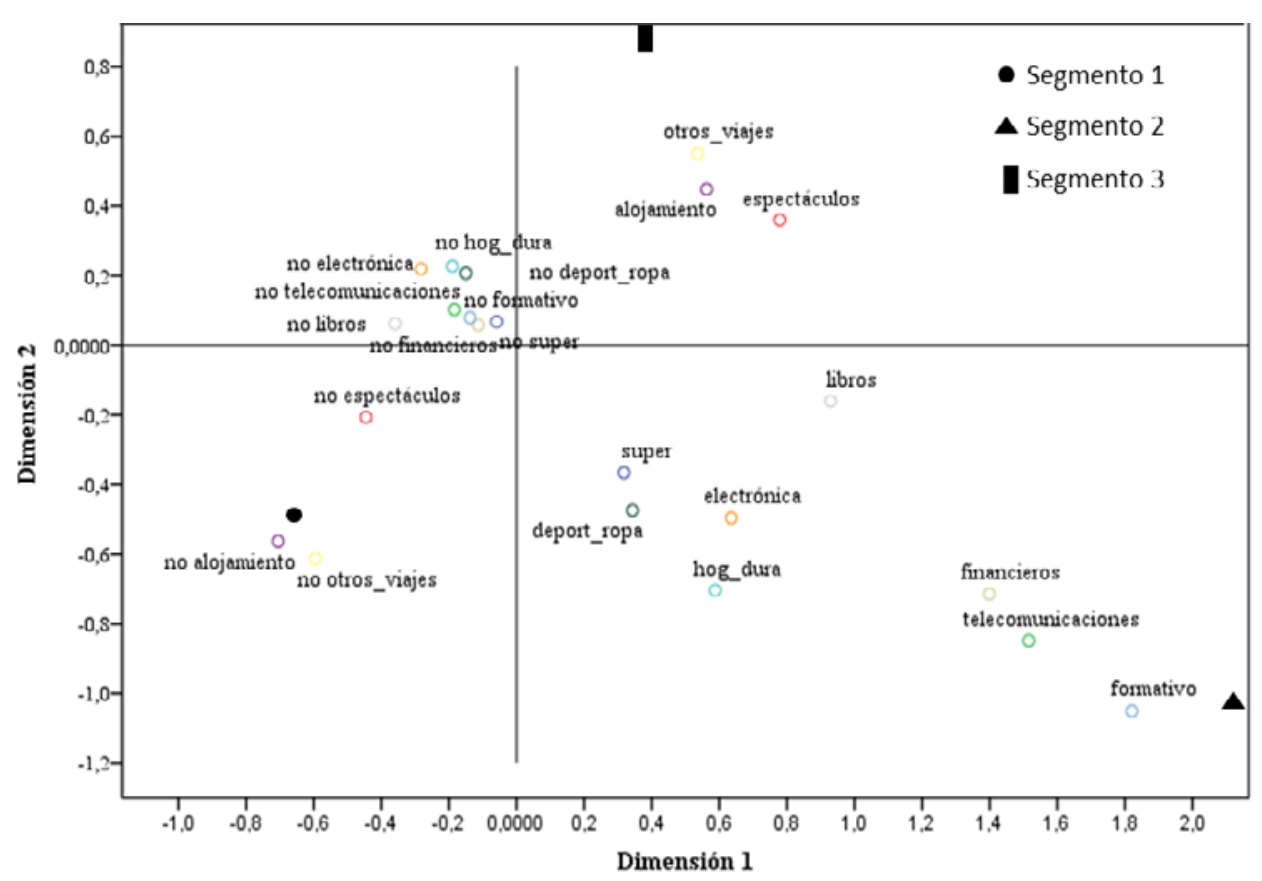

Fuente: elaboración propia. 


\section{RESULTADOS: LA SEGMENTACIÓN DE LOS CONSUMIDORES SENIORS EN LÍNEA}

Como se observa en las Tablas 5, 6 y 7, el primer segmento, que representa el 51,7\% del total de individuos que compran servicios o productos a través de Internet, es el menos activo, y el que compra menos. Utiliza Internet sobre todo para comprar material deportivo y ropa $(30,7 \%$ del total de individuos del segmento) y equipamiento electrónico $(27,2 \%)$. El segmento 2, el más pequeño, es el más activo y el que compra más diversidad de productos o servicios. Prácticamente compra de todo a través de Internet. Finalmente, el segmento 3 (40,9\% del total de seniors que compran por Internet), compra sobre todo productos y servicios turísticos (alojamiento y otros servicios relacionados con los viajes), y espectáculos.

Tabla 5

SEGMENTOS Y VARIABLES ACTIVAS PARA LA SEGMENTACIÓN (\% POR SEGMENTOS)

\begin{tabular}{|l|l|c|c|c|}
\hline & & Segmento 1 & Segmento 2 & Segmento 3 \\
\hline $\begin{array}{l}\text { Productos de alimentación y de } \\
\text { consumo no duraderos (super) }\end{array}$ & No compra & 84,2 & 71,9 & 86,8 \\
\cline { 2 - 5 } & Sí compra & 15,8 & 28,1 & 13,2 \\
\hline $\begin{array}{l}\text { Bienes para el hogar (hog_ } \\
\text { dura) }\end{array}$ & No compra & 77,5 & 31,2 & 81,1 \\
\cline { 2 - 5 } & Sí compra & 22,5 & 68,8 & 18,9 \\
\hline $\begin{array}{l}\text { Películas, música, libros, } \\
\text { revistas, periódicos (libros) }\end{array}$ & No compra & 84,2 & 15,6 & 67,0 \\
\cline { 2 - 5 } & Sí compra & 15,8 & 84,4 & 33,0 \\
\hline \multirow{2}{*}{\begin{tabular}{l} 
Material formativo (formativo) \\
\cline { 2 - 5 }
\end{tabular}} & No compra & 97,3 & 45,3 & 96,1 \\
\hline $\begin{array}{l}\text { Material deportivo, ropa } \\
\text { (deport_ropa) }\end{array}$ & No compra & 69,7 & 54,7 & 3,9 \\
\cline { 2 - 5 } & Sí compra & 30,7 & 59,4 & 24,8 \\
\hline $\begin{array}{l}\text { Juegos de ordenador o } \\
\text { videoconsolas, software de } \\
\text { ordenador y actualizaciones; } \\
\text { equipo informático; } \\
\text { equipamiento electrónico } \\
\text { (electrónica) }\end{array}$ & No compra & 72,8 & 21,9 & 73,2 \\
\cline { 2 - 5 } & Sí compra & 27,2 & 78,1 & 26,8 \\
\hline $\begin{array}{l}\text { Servicios de } \\
\text { telecomunicaciones } \\
\text { (telecomunicaciones) }\end{array}$ & Sí compra & 6,5 & 64,1 & 6,8 \\
\hline $\begin{array}{l}\text { Acciones, pólizas de seguros } \\
\text { u otros servicios financieros } \\
\text { (financieros) }\end{array}$ & No compra & 96,0 & 57,8 & 94,4 \\
\cline { 2 - 5 } & Sí compra & 4,0 & 42,2 & 5,6 \\
\hline \multirow{2}{*}{ No compra } & 93,5 & 35,9 & 93,2 \\
\hline
\end{tabular}




\begin{tabular}{|l|l|c|c|c|}
\hline & & Segmento 1 & Segmento 2 & Segmento 3 \\
\hline $\begin{array}{l}\text { Alojamiento de vacaciones } \\
\text { (alojamiento) }\end{array}$ & No compra & 80,4 & 1,6 & 6,5 \\
\cline { 2 - 5 } & Sí compra & 19,6 & 98,4 & 93,5 \\
\hline \multirow{2}{*}{$\begin{array}{l}\text { Otros servicios de viajes } \\
\text { (otros_viajes) }\end{array}$} & No compra & 82,9 & 7,8 & 9,6 \\
\cline { 2 - 5 } & Sí compra & 17,1 & 92,2 & 90,4 \\
\hline $\begin{array}{l}\text { Entradas para espectáculos } \\
\text { (espectáculos) }\end{array}$ & No compra & 87,3 & 23,4 & 40,8 \\
\cline { 2 - 5 } & Sí compra & 12,7 & 76,6 & 59,2 \\
\hline
\end{tabular}

Fuente: elaboración propia.

En cuanto al gasto aproximado que cada clúster realiza en compras por Internet, observamos que el segmento 2 es el que más gasta, el 24,6\% de los miembros afirman haber gastado más de 1.000 euros en compras realizadas en los últimos 3 meses. El segmento 1 es el que menos gasta. Casi el $90 \%$ de los miembros de este segmento, afirman haber gastado hasta $500 €$ en los últimos 3 meses. Finalmente, el $66 \%$ de los miembros del segmento 3 afirman haber gastado hasta $1.000 €$ en compras por Internet en los últimos 3 meses. Estas cifras son realmente significativas teniendo en cuenta que según los datos ofrecidos por el Observatorio Nacional de las Telecomunicaciones y de la Sociedad de la Información (2015a), el gasto medio anual en compras virtuales por un internauta en España en el año 2014 fue de $876 €$. En referencia al número de veces que han comprado por Internet, de nuevo, se observa que el segmento 1 es el menos activo y el segmento 2 el que más.

Tabla 6

VALOR APROXIMADO DE LAS COMPRAS REALIZADAS EN LOS ÚLTIMOS 3 MESES POR SEGMENTO (\%)

\begin{tabular}{|l|c|c|c|}
\hline & Segmento 1 & Segmento 2 & Segmento 3 \\
\hline Menos de 50 euros & 22,6 & 0,0 & 5,3 \\
\hline De 50 a menos de 100 & 33,9 & 15,8 & 19,0 \\
\hline De 100 a menos de 500 & 33,2 & 45,6 & 44,5 \\
\hline De 500 a menos de 1.000 & 4,3 & 12,3 & 22,1 \\
\hline 1.000 cursos o más & 3,0 & 24,6 & 5,3 \\
\hline NS/NR & 3,0 & 1,8 & 3,8 \\
\hline
\end{tabular}

Fuente: elaboración propia.

Todas las relaciones entre la variable de clasificación y las variables ilustrativas (valor aproximado gastado y número de veces que han comprado) son significativas al $1 \%$ (p-valor $<0,01)$. 
Tabla 7

FRECUENCIA DE COMPRA POR INTERNET EN LOS ÚLTIMOS 3 MESES POR SEGMENTO (\%)

\begin{tabular}{|l|c|c|c|}
\hline & Segmento 1 & Segmento 2 & Segmento 3 \\
\hline 1 ó 2 veces & 72,4 & 19,3 & 45,2 \\
\hline De 3 a 5 veces & 19,6 & 49,1 & 41,4 \\
\hline De 6 a 10 veces & 5,0 & 15,8 & 10,3 \\
\hline Más de 10 veces & 3,0 & 15,8 & 3,0 \\
\hline
\end{tabular}

Fuente: elaboración propia.

Fruto de los resultados obtenidos podemos denominar al segmento 1 como "Comprador esporádico en línea"; al segmento 2 como: "Gran comprador en línea"; y al segmento 3 como "Comprador de turismo en Internet".

A continuación se presentan los resultados de los tres segmentos, junto con el grupo de individuos que no compran a través de Internet $(\mathrm{n}=2.541)$, haciendo hincapié sobre todo en el segmento que compra productos o servicios de turismo, para definirlo y conocer cómo se comporta con relación al uso de Internet en general. En la Tabla 8 se observa que las personas mayores de 54 años que no compran a través de Internet representan el 65,8\%.

Tabla 8

PERFIL DE COMPRA EN LÍNEA DE LOS SENIORS

\begin{tabular}{|l|c|c|}
\hline Segmento & Frecuencia & \% \\
\hline No compradores & 1.673 & 65,8 \\
\hline Comprador esporádico en línea & 449 & 17,7 \\
\hline Gran comprador en línea & 64 & 2,5 \\
\hline Comprador de productos turísticos en Internet & 355 & 14,0 \\
\hline Total & 2.451 & 100 \\
\hline
\end{tabular}

Fuente: elaboración propia.

En este caso, también todas las relaciones entre las variables ilustrativas y los segmentos son significativas a $\alpha=1 \%$.

En cuanto a las variables sociodemográficas (ver Tabla 9) se observa que los miembros de los segmentos que compran de todo (s2) y los que compran productos o servicios turísticos (s3) son más jóvenes (60,6 y 60,7 años de media, respectivamente) que los que compran poco (s1) (61,2 años), y que los que no compran a través de Internet (63,6 años). En cuanto al género hay diferencias muy significativas entre segmentos. Observamos que los hombres tienen más tendencia a comprar por Internet. El 56,1\% de los miembros del segmento que compra turismo son hombres, y el $81,3 \%$ del segmento que compra de todo también. 
Tabla 9

VARIABLES SOCIODEMOGRÁFICAS POR SEGMENTO Y CATEGORÍA (\%)

\begin{tabular}{|c|c|c|c|c|c|}
\hline Variable & $\begin{array}{c}\text { Categoría de la } \\
\text { variable }\end{array}$ & $\begin{array}{c}\text { No } \\
\text { compran }\end{array}$ & $\begin{array}{l}\text { Compran } \\
\text { poco }(\mathrm{S} 1)\end{array}$ & $\begin{array}{l}\text { Compran } \\
\text { de } \\
\text { Todo (S2) }\end{array}$ & $\begin{array}{c}\text { Compran } \\
\text { Turismo } \\
\text { (S3) }\end{array}$ \\
\hline \begin{tabular}{|l} 
Media de \\
edad en años \\
(Desviación \\
Típica)
\end{tabular} & & $\begin{array}{c}63,6 \\
(7,27)\end{array}$ & $\begin{array}{c}61,2 \\
(6,48)\end{array}$ & $\begin{array}{c}60,6 \\
(4,71)\end{array}$ & $\begin{array}{c}60,7 \\
(5,61)\end{array}$ \\
\hline \multirow{2}{*}{ Género } & Hombre & 44,1 & 53,9 & 81,3 & 56,1 \\
\hline & Mujer & 55,9 & 46,1 & 18,7 & 43,9 \\
\hline \multirow{3}{*}{$\begin{array}{l}\text { Nivel de } \\
\text { estudios }\end{array}$} & Hasta estudios secund. & 78,3 & 61,8 & 26,6 & 41,4 \\
\hline & Estudios universitarios & 21,5 & 38,1 & 73,4 & 58,6 \\
\hline & $\mathrm{Ns} / \mathrm{Nr}$ & 0,2 & 0,0 & 0,0 & 0,0 \\
\hline \multirow{6}{*}{$\begin{array}{l}\text { Ingresos } \\
\text { mensuales } \\
\text { netos del hogar }\end{array}$} & Menos de $900 €$ & 16,0 & 9,6 & 0,0 & 1,7 \\
\hline & De 900 a $1.600 €$ & 30,1 & 24,3 & 10,9 & 14,4 \\
\hline & De 1.600 a $2.500 €$ & 21,1 & 23,4 & 32,8 & 26,8 \\
\hline & De 2.500 a $3.000 €$ & 5,1 & 9,8 & 15,6 & 13,5 \\
\hline & 3.000 € o más & 5,4 & 11,6 & 29,7 & 28,2 \\
\hline & $\mathrm{Ns} / \mathrm{Nr}$ & 22,3 & 21,4 & 10,9 & 15,5 \\
\hline \multirow{5}{*}{$\begin{array}{l}\text { Situación } \\
\text { laboral en } \\
\text { la que se } \\
\text { encuentra }\end{array}$} & Trabajando & 31,6 & 46,3 & 60,9 & 56,6 \\
\hline & Parado & 9,7 & 9,4 & 6,3 & 8,2 \\
\hline & Jubilado o incapacitado & 43,9 & 37,2 & 31,2 & 30,4 \\
\hline & Labores del hogar & 13,1 & 5,6 & 0,0 & 3,1 \\
\hline & Otra situación & 1,7 & 1,5 & 1,6 & 1,7 \\
\hline
\end{tabular}

Fuente: elaboración propia.

En referencia a la educación se observa que a nivel de estudios más altos, más compras se realizan por Internet. El 58,6\% de los que compran productos o servicios de turismo tienen estudios universitarios. Estos resultados concuerdan con otros estudios previos como los realizados por Villarejo et al. (2016) o Cristóbal-Fransi et al. (2015). Por otro lado, también se observan diferencias importantes entre segmentos referentes al nivel de ingresos del hogar. Los segmentos que usan más Internet para comprar, son los que muestran ingresos más elevados. El 28,2\% de los miembros del segmento que compra turismo, afirma ingresar $3.000 €$ o más al mes. Finalmente, observamos que el 56,6\% de los miembros del segmento que compra productos turísticos está aún trabajando y el 30,4\% está jubilado o incapacitado.

En la Tabla 10 referente a las variables de comportamiento respecto al uso de Internet, se observa que el $4 \%$ de los seniors que no compran a través de la Red, afirma haber usado Internet hace un mes o más, el resto, lo usan más a menudo. De hecho, la gran mayoría de los seniors que compran productos o servicios a través de Internet, se conectan a diario. El grado de confianza en la Red también está relacionado con el grado de actividad de los usuarios. El 72,4\% de los miembros del segmento que compra turismo confían bastante en Internet, y el 7,9\% confía mucho. 
Tabla 10

VARIABLES DE COMPORTAMIENTO DE USO DE INTERNET, POR SEGMENTO Y CATEGORÍA $(\%)$

\begin{tabular}{|c|c|c|c|c|c|}
\hline Variable & $\begin{array}{l}\text { Categoría de la } \\
\text { variable }\end{array}$ & $\begin{array}{c}\text { No } \\
\text { compran }\end{array}$ & $\begin{array}{l}\text { Compran } \\
\text { poco }(\mathrm{S} 1)\end{array}$ & $\begin{array}{c}\text { Compran de } \\
\text { Todo (S2) }\end{array}$ & $\begin{array}{c}\text { Compran } \\
\text { Turismo } \\
\text { (S3) } \\
\end{array}$ \\
\hline \multirow{2}{*}{$\begin{array}{l}\text { Última vez que usó } \\
\text { Internet }\end{array}$} & Último mes & 96,1 & 99,1 & 100,0 & 100,0 \\
\hline & $\begin{array}{l}\text { Más de } 1 \text { mes y } \\
\text { menos de } 3\end{array}$ & 3,9 & 0,9 & 0,0 & 0,0 \\
\hline \multirow{3}{*}{$\begin{array}{l}\text { Frecuencia de uso } \\
\text { de Internet (últimos } \\
\text { tres meses) }\end{array}$} & \begin{tabular}{|l|} 
Diariamente, 5 \\
días por semana \\
\end{tabular} & 58,6 & 82,0 & 100,0 & 90,1 \\
\hline & $\begin{array}{l}\text { Todas las } \\
\text { semanas } \\
\end{array}$ & 27,8 & 15,8 & 0,0 & 8,5 \\
\hline & \begin{tabular}{|l|} 
Menos de una \\
vez a la semana \\
\end{tabular} & 13,6 & 2,2 & 0,0 & 1,4 \\
\hline \multirow{3}{*}{$\begin{array}{l}\text { Grado de confianza } \\
\text { en Internet }\end{array}$} & Poco o nada & 46,4 & 29,0 & 6,2 & 19,7 \\
\hline & Bastante & 48,6 & 61,7 & 67,2 & 72,4 \\
\hline & \begin{tabular}{|l|} 
Mucho \\
\end{tabular} & 5,0 & 9,4 & 26,6 & 7,9 \\
\hline \multirow{2}{*}{$\begin{array}{l}\text { Servicio usado: } \\
\text { correo electrónico }\end{array}$} & No usa Internet & 38,0 & 11,1 & 0,0 & 3,9 \\
\hline & Sí usa Internet & 62,0 & 88,9 & 100,0 & 96,1 \\
\hline \multirow{2}{*}{$\begin{array}{l}\text { Servicio usado: } \\
\text { telefonear o vídeo } \\
\text { llamada }\end{array}$} & No usa Internet & 84,6 & 74,2 & 53,1 & 63,1 \\
\hline & Sí usa Internet & 15,4 & 25,8 & 46,9 & 36,9 \\
\hline \multirow{2}{*}{$\begin{array}{l}\text { Servicio usado: } \\
\text { participar en redes } \\
\text { sociales }\end{array}$} & No usa Internet & 68,2 & 55,0 & 35,9 & 52,4 \\
\hline & Sí usa Internet & 31,8 & 45,0 & 64,1 & 47,6 \\
\hline \multirow{2}{*}{$\begin{array}{l}\text { Servicio usado: } \\
\text { colgar contenidos } \\
\text { propios }\end{array}$} & No usa Internet & 87,0 & 73,9 & 50,0 & 68,5 \\
\hline & Sí usa Internet & 13,0 & 26,1 & 50,0 & 31,5 \\
\hline \multirow{2}{*}{$\begin{array}{l}\text { Servicio usado: } \\
\text { crear páginas web } \\
\text { o blogs }\end{array}$} & No usa Internet & 99,5 & 96,4 & 76,6 & 94,1 \\
\hline & Sí usa Internet & 0,5 & 3,6 & 23,4 & 5,9 \\
\hline \multirow{2}{*}{$\begin{array}{l}\text { Servicio usado: } \\
\text { leer noticias, } \\
\text { periódicos, revistas }\end{array}$} & No usa Internet & 29,7 & 15,4 & 0,0 & 9,9 \\
\hline & Sí usa Internet & 70,3 & 84,6 & 100,0 & 90,1 \\
\hline \multirow{2}{*}{$\begin{array}{l}\text { Servicio usado: } \\
\text { buscar información } \\
\text { sobre salud }\end{array}$} & No usa Internet & 46,7 & 31,8 & 7,8 & 25,1 \\
\hline & Sí usa Internet & 53,3 & 68,2 & 92,2 & 74,9 \\
\hline \multirow{2}{*}{$\begin{array}{l}\text { Servicio usado: } \\
\text { buscar información } \\
\text { sobre educación }\end{array}$} & No usa Internet & 65,1 & 50,1 & 17,2 & 34,9 \\
\hline & Sí usa Internet & 34,9 & 49,9 & 82,2 & 65,1 \\
\hline
\end{tabular}




\begin{tabular}{|c|c|c|c|c|c|}
\hline Variable & $\begin{array}{l}\text { Categoría de la } \\
\text { variable }\end{array}$ & $\begin{array}{c}\text { No } \\
\text { compran }\end{array}$ & $\begin{array}{l}\text { Compran } \\
\text { poco }(\mathrm{S} 1)\end{array}$ & $\begin{array}{l}\text { Compran de } \\
\text { Todo (S2) }\end{array}$ & $\begin{array}{c}\text { Compran } \\
\text { Turismo } \\
\text { (S3) } \\
\end{array}$ \\
\hline \multirow{2}{*}{$\begin{array}{l}\text { Servicio usado: } \\
\text { consultar wikis }\end{array}$} & No usa Internet & 57,0 & 31,8 & 12,5 & 17,7 \\
\hline & Sí usa Internet & 43,0 & 68,2 & 87,5 & 82,3 \\
\hline \multirow{2}{*}{$\begin{array}{l}\text { Servicio usado: } \\
\text { buscar información } \\
\text { sobre bienes/ } \\
\text { servicios }\end{array}$} & No usa Internet & 53,2 & 29,2 & 1,6 & 16,6 \\
\hline & Sí usa Internet & 46,8 & 70,8 & 98,4 & 83,4 \\
\hline \multirow{2}{*}{$\begin{array}{l}\text { Servicio usado: } \\
\text { descargar software }\end{array}$} & No usa Internet & 91,9 & 77,7 & 50,0 & 67,0 \\
\hline & Sí usa Internet & 8,1 & 22,3 & 50,0 & 33,0 \\
\hline \multirow{2}{*}{$\begin{array}{l}\text { Servicio usado: } \\
\text { escuchar la radio }\end{array}$} & No usa Internet & 85,8 & 68,4 & 37,5 & 63,9 \\
\hline & Sí usa Internet & 14,2 & 31,6 & 62,5 & 36,1 \\
\hline \multirow{2}{*}{$\begin{array}{l}\text { Servicio usado: ver } \\
\text { vídeos o películas }\end{array}$} & No usa Internet & 74,2 & 58,8 & 32,8 & 52,4 \\
\hline & Sí usa Internet & 25,8 & 41,2 & 67,2 & 47,6 \\
\hline \multirow{2}{*}{$\begin{array}{l}\text { Servicio } \\
\text { usado: viajes y } \\
\text { alojamiento }\end{array}$} & No usa Internet & 68,1 & 44,5 & 3,1 & 9,6 \\
\hline & Sí usa Internet & 31,9 & 55,5 & 96,9 & 90,4 \\
\hline \multirow{2}{*}{$\begin{array}{l}\text { Servicio usado: } \\
\text { vender bienes o } \\
\text { servicios }\end{array}$} & No usa Internet & 96,7 & 87,8 & 78,1 & 84,5 \\
\hline & Sí usa Internet & 3,3 & 12,2 & 21,9 & 15,5 \\
\hline \multirow{2}{*}{$\begin{array}{l}\text { Servicio usado: } \\
\text { banca electrónica }\end{array}$} & No usa Internet & 72,3 & 35,9 & 4,7 & 20,8 \\
\hline & Sí usa Internet & 27,7 & 64,1 & 95,3 & 79,2 \\
\hline \multirow{2}{*}{$\begin{array}{l}\text { Servicio usado: } \\
\text { descargar juegos, } \\
\text { música, imágenes, } \\
\text { películas }\end{array}$} & No usa Internet & 65,6 & 48,8 & 29,7 & 42,5 \\
\hline & Sí usa Internet & 34,4 & 51,2 & 70,3 & 57,7 \\
\hline \multirow{2}{*}{$\begin{array}{l}\text { Uso de teléfono } \\
\text { móvil para acceder } \\
\text { a Internet fuera } \\
\text { de la vivienda o } \\
\text { trabajo }\end{array}$} & No usa teléfono & 46,9 & 31,2 & 12,5 & 17,5 \\
\hline & Sí usa teléfono & 53,1 & 68,8 & 87,5 & 82,5 \\
\hline \multirow{2}{*}{$\begin{array}{l}\text { Uso de ordenador } \\
\text { portátil para } \\
\text { acceder a Internet } \\
\text { fuera de la vivienda } \\
\text { o trabajo }\end{array}$} & No usa portátil & 86,8 & 72,4 & 39,1 & 61,1 \\
\hline & Sí usa portátil & 13,2 & 27,6 & 60,9 & 38,9 \\
\hline \multirow{3}{*}{$\begin{array}{l}\text { Dispone de lector } \\
\text { de e-books en la } \\
\text { vivienda }\end{array}$} & No dispone & 76,6 & 63,5 & 37,5 & 49,3 \\
\hline & Sí dispone & 22,9 & 36,1 & 62,5 & 50,7 \\
\hline & $\mathrm{Ns} / \mathrm{Nr}$ & 0,5 & 0,4 & 0,0 & 0,0 \\
\hline
\end{tabular}

Fuente: elaboración propia. 
Al analizar el comportamiento de los segmentos que compran por Internet, se ha creído relevante también analizar qué actividades realizan mayoritariamente en Internet. Los resultados muestran diferencias significativas entre segmentos, así pues el segmento "compra de todo" (S2) es el más activo a Internet y realiza la mayoría de las actividades analizadas. El segmento que compra turismo (S3) mayoritariamente utiliza Internet para consultar el correo electrónico $(96,1 \%)$, para leer noticias, periódicos y revistas $(90,1 \%)$, consultar wikis $(82,3 \%)$, buscar información sobre bienes/servicios $(83,4 \%)$, utilizar servicios relacionados con viajes y alojamientos $(90,4 \%)$ y actividades de banca electrónica $(79,2 \%)$.

También se relacionan los segmentos con las variables relativas al uso de otros dispositivos electrónicos. Se observa que el teléfono móvil es más usado que el portátil para acceder a Internet, y sobretodo lo usan los que compran de todo $(87,5 \%)$ y los que compran productos y servicios de turismo $(82,5 \%)$.

Tabla 11

PROBLEMAS DE SEGURIDAD EXPERIMENTADOS Y CONOCIMIENTOS INFORMÁTICOS POR SEGMENTO Y CATEGORÍA (\%)

\begin{tabular}{|l|l|c|c|c|c|}
\hline \multicolumn{1}{|c|}{ Variable } & $\begin{array}{l}\text { Categoría de } \\
\text { la variable }\end{array}$ & $\begin{array}{c}\text { No } \\
\text { compran }\end{array}$ & $\begin{array}{c}\text { Compran } \\
\text { poco (S1) }\end{array}$ & $\begin{array}{c}\text { Compran } \\
\text { de } \\
\text { Todo (S2) }\end{array}$ & $\begin{array}{c}\text { Compran } \\
\text { Turismo } \\
\text { (S3) }\end{array}$ \\
\hline $\begin{array}{l}\text { Problemas seguridad: } \\
\text { virus con pérdida de } \\
\text { información y tiempo }\end{array}$ & No problemas & 85,2 & 73,9 & 84,4 & 74,4 \\
\cline { 2 - 6 } & Sí problemas & 14,8 & 26,1 & 15,6 & 25,6 \\
\hline $\begin{array}{l}\text { Problemas seguridad: } \\
\text { recibir spam }\end{array}$ & No problemas & 62,8 & 35,6 & 12,5 & 25,6 \\
\cline { 2 - 6 } $\begin{array}{l}\text { Problemas seguridad: } \\
\text { abusos sobre } \\
\text { información personal }\end{array}$ & No problemas & 97,6 & 94,7 & 87,5 & 90,1 \\
\cline { 2 - 6 } & Sí problemas & 2,4 & 5,3 & 12,5 & 9,9 \\
\hline $\begin{array}{l}\text { Problemas seguridad: } \\
\text { pérdidas económicas } \\
\text { por phishing o } \\
\text { pharming }\end{array}$ & No problemas & 99,0 & 97,6 & 100,0 & 97,2 \\
\cline { 2 - 6 } & Sí problemas & 1,0 & 2,4 & 0,0 & 2,8 \\
\hline $\begin{array}{l}\text { Problemas seguridad: } \\
\text { pérdidas económicas } \\
\text { uso fraudulento tarjetas }\end{array}$ & No problemas & 99,4 & 98,0 & 98,4 & 97,5 \\
\cline { 2 - 6 } & Sí problemas & 0,6 & 2,0 & 1,6 & 2,5 \\
\hline $\begin{array}{l}\text { Conocimientos } \\
\text { informáticos: transferir } \\
\text { ficheros entre } \\
\text { ordenador y otros } \\
\text { dispositivos }\end{array}$ & No realiza & 69,3 & 42,1 & 4,7 & 19,2 \\
\cline { 2 - 6 } & Sí realiza & 30,7 & 57,9 & 95,3 & 80,8 \\
\hline
\end{tabular}




\begin{tabular}{|c|c|c|c|c|c|}
\hline Variable & $\begin{array}{l}\text { Categoría de } \\
\text { la variable }\end{array}$ & $\begin{array}{c}\text { No } \\
\text { compran }\end{array}$ & $\begin{array}{l}\text { Compran } \\
\text { poco (S1) }\end{array}$ & $\begin{array}{l}\text { Compran } \\
\text { de } \\
\text { Todo (S2) }\end{array}$ & $\begin{array}{c}\text { Compran } \\
\text { Turismo } \\
\text { (S3) }\end{array}$ \\
\hline \multirow{2}{*}{$\begin{array}{l}\text { Conocimientos } \\
\text { informáticos: instalar } \\
\text { software o aplicaciones }\end{array}$} & No realiza & 85,0 & 60,1 & 25,0 & 38,6 \\
\hline & Sí realiza & 15,0 & 39,9 & 75,0 & 61,4 \\
\hline \multirow{2}{*}{$\begin{array}{l}\text { Conocimientos } \\
\text { informáticos: cambiar } \\
\text { configuración software }\end{array}$} & No realiza & 95,8 & 83,1 & 53,1 & 76,3 \\
\hline & Sí realiza & 4,2 & 16,9 & 46,9 & 23,7 \\
\hline \multirow{2}{*}{$\begin{array}{l}\text { Conocimientos } \\
\text { informáticos: copiar } \\
\text { o mover ficheros o } \\
\text { carpetas }\end{array}$} & No realiza & 60,0 & 31,2 & 4,7 & 12,1 \\
\hline & Sí realiza & 40,0 & 68,8 & 95,3 & 87,9 \\
\hline \multirow{2}{*}{$\begin{array}{l}\text { Conocimientos } \\
\text { informáticos: usar } \\
\text { procesador de texto }\end{array}$} & No realiza & 67,0 & 34,5 & 4,7 & 16,9 \\
\hline & Sí realiza & 33,0 & 65,5 & 95,3 & 83,1 \\
\hline \multirow{2}{*}{$\begin{array}{l}\text { Conocimientos } \\
\text { informáticos: crear } \\
\text { presentaciones o } \\
\text { documentos que } \\
\text { integren ficheros } \\
\text { diferentes }\end{array}$} & No realiza & 85,3 & 63,0 & 23,4 & 48,7 \\
\hline & Sí realiza & 14,7 & 37,0 & 76,6 & 51,3 \\
\hline \multirow{2}{*}{$\begin{array}{l}\text { Conocimientos } \\
\text { informáticos: usar hojas } \\
\text { de cálculo }\end{array}$} & No realiza & 82,2 & 55,2 & 17,2 & 41,1 \\
\hline & Sí realiza & 17,8 & 44,8 & 82,8 & 58,9 \\
\hline \multirow{2}{*}{$\begin{array}{l}\text { Conocimientos } \\
\text { informáticos: usar } \\
\text { software para editar } \\
\text { fotos, vídeos o audios }\end{array}$} & No realiza & 85,8 & 63,9 & 25,0 & 55,2 \\
\hline & Sí realiza & 14,2 & 36,1 & 75,0 & 44,8 \\
\hline \multirow{2}{*}{$\begin{array}{l}\text { Conocimientos } \\
\text { informáticos: } \\
\text { programar lenguaje de } \\
\text { programación }\end{array}$} & No realiza & 99,6 & 97,8 & 85,9 & 94,9 \\
\hline & Sí realiza & 0,4 & 2,2 & 14,1 & 5,1 \\
\hline
\end{tabular}

Fuente: elaboración propia.

En referencia a la relación entre el uso de Internet para comprar productos o servicios y los problemas de seguridad (Tabla 11), observamos que en general los que más compran menos problemas experimentan. Por otro lado, al relacionar los conocimientos informáticos de los usuarios y los segmentos de compra por Internet, se observa que los segmentos más activos a la hora de comprar por Internet (los que compran de todo y los que compran productos o servicios turísticos), son también los segmentos que más conocimientos 
informáticos tienen. En el caso de los que compran productos turísticos, cabe destacar la realización de tareas como transferir ficheros entre ordenadores y otros dispositivos, copiar o mover ficheros o carpetas y usar procesadores de texto.

Si nos fijamos, a continuación, con los motivos de no haber comprado por Internet en los últimos tres meses (Tabla 12), destacan sobre todo porqué prefieren comprar en tienda física, por falta de habilidades o conocimientos y porqué les preocupa la privacidad o seguridad en el pago.

Tabla 12

MOTIVOS POR NO HABER COMPRADO A TRAVÉS DE INTERNET (\%)

\begin{tabular}{|l|c|}
\hline Motivos por no haber comprado bienes o servicios por Internet & \% \\
\hline Prefiere tienda física & 82,5 \\
\hline Falta de habilidades o conocimientos & 41,1 \\
\hline Entrega problemática & 9,7 \\
\hline Preocupa la privacidad o seguridad en el pago & 40,8 \\
\hline Falta de confianza en la recepción o devolución & 27,4 \\
\hline No disposición de tarjeta de pago & 7,4 \\
\hline Porque los vendedores extranjeros no atienden pedidos en España & 1,7 \\
\hline Otras razones & 18,2 \\
\hline
\end{tabular}

Fuente: elaboración propia.

\section{CONCLUSIONES FINALES}

Los resultados obtenidos en la presente investigación pretenden ser una aportación original y rellenar el gran hueco que hay en las investigaciones centradas en el colectivo de personas mayores y su comportamiento frente a la compra en línea en general y la adquisición de productos y servicios turísticos en Internet en particular. El hecho de considerar tres segmentos de internautas seniors nos sugiere que desde las empresas turísticas y las administraciones públicas no se pueden permitir el lujo de considerar a este grupo como un todo, con un perfil único. Es necesario segmentar este grupo de consumidores para poder llegar de una manera efectiva a este mercado ya sea con propósitos comerciales, administrativos e incluso los relacionados con la sanidad.

Este trabajo ha propuesto una segmentación de los usuarios senior de Internet, en base a su comportamiento de compra en Internet fruto de la explotación de los resultados de una amplia encuesta realizada por el Instituto Nacional de Estadística a más de 15.000 hogares. Los segmentos diferenciados han sido tres:

1) “Comprador esporádico en línea". Este es un consumidor de mayor edad y con menos estudios, que utiliza en menor medida las posibilidades de Internet. Este es un colectivo que si bien ha superado la brecha digital ya que se sus miembros se conectan a Internet, necesitan un mayor esfuerzo tanto por parte de las administraciones públi- 
cas, como por parte de las empresas para poder incorporarlos en este nuevo mercado con todos sus recursos. De esta manera pasarían de ser meros espectadores, a ser unos consumidores más activos. Para ello, se debe mejorar la comunicación para aumentar la confianza en el medio, y la formación, para facilitar el uso tanto del equipamiento informático como de la Red en sí.

2) "Gran comprador en línea". Los miembros de este grupo son los seniors más jóvenes, son usuarios más formados, que utilizan los recursos que ofrece Internet y compran una amplia categoría de productos. Estos usuarios se conectan con una gran frecuencia, cuentan con una gran confianza en el medio y son los que más gastan en sus compras en línea. Las empresas deben cuidar a este colectivo e intentar ajustar su oferta a sus necesidades ya que es el segmento que ofrece más posibilidades. También es cierto que es el menos numeroso.

3) "Comprador de turismo en Internet". Los usuarios de este segmento presentan un buen nivel de conocimientos informáticos, utilizan la Red para comunicarse y para buscar información tanto de noticias en general como información de bienes y servicios en particular. Este es el colectivo más orientado a la búsqueda de información y la compra de productos y servicios turísticos a través de la Red. Por tanto, el conocimiento del perfil de este segmento es clave tanto para la empresa turística como para los organismos que gestionan los recursos y destinos turísticos para poder diseñar una oferta atractiva y una estrategia de comunicación en línea efectiva.

Los individuos de los tres grupos presentan un perfil demográfico variado y una actitud bien diferenciada respecto al uso de Internet. Por otro lado, no podemos obviar que el grupo de usuarios que no compran productos o servicios a través de Internet, también presentan unas características particulares y distintas. Este grupo es el más amplio comparado con los otros segmentos que sí utilizan Internet para comprar productos o servicios. Presentan una media de edad más elevada, un nivel de estudios inferior y un nivel de ingresos mensuales netos también inferiores. A nivel de ocupación, en este colectivo un porcentaje más elevado afirma estar jubilado o incapacitado, o realizar labores del hogar. A la vista de los resultados podemos exponer que la gestión de un negocio virtual llevada a cabo como si fuera una extensión más de una actividad tradicional puede ser un importante motivo de fracaso comercial. Toda iniciativa de comercio electrónico se tiene que adaptar tanto a la realidad del medio como a la de los usuarios del mismo.

El turista senior utiliza en su mayor parte canales indirectos para contratar sus viajes como los tour operadores, agencias de viaje u organismos públicos; pero en la actualidad ya se observa un incremento en el uso de canales electrónicos tanto para la planificación como para la adquisición de los productos turísticos. Podríamos hablar también de cierta seguridad en la compra de productos o servicios turísticos, por el hecho que los usuarios miembros del tercer segmento adquieren servicios que implican un riesgo en cuanto a las posibles diferencias entre el servicio comprado y el servicio consumido, y el precio pagado que suele ser elevado (es el caso del alojamiento de vacaciones). Por otro lado, adquirir entradas para espectáculos no implica un riesgo demasiado elevado y parece que los turistas seniors se sienten cómodos con Internet. En todo caso, el $72,4 \%$ de los seniors incluidos en el tercer segmento, se muestran bastante confiados 
en Internet y según el trabajo de Amaro y Duarte (2013), la confianza y la seguridad ejercen una gran influencia y representan un claro antecedente de la compra online.

Se prevé que en el futuro, dado el mayor manejo y convivencia con las tecnologías de información y comunicación por parte de los mayores, este canal directo en línea tendrá un mayor peso en la comercialización de servicios turísticos (Alen et al., 2010). La industria turística no puede ignorar las oportunidades de mercado de los mayores, ya que es un colectivo en constante crecimiento, que cada vez se encuentra en mejores condiciones físicas e intelectuales, con un mayor poder adquisitivo y con un creciente interés en viajar. Pero también hay que indicar que es un segmento cada vez más formado y con un mayor conocimiento y dominio de las tecnologías de la información y la comunicación (Alen et al., 2014). Por tanto conocer las características, intereses y motivaciones de los turistas senior es clave para la empresa turística a la hora del diseño y desarrollo de nuevos negocios y paquetes turísticos.

Centrándonos en el grupo de seniors que no compran a través de Internet, estos pueden representar unos clientes potenciales para aquellos negocios que a la hora de llevar a cabo iniciativas de comercio electrónico se adapten también a la realidad de dicho usuarios, ya que utilizan Internet igualmente, sobre todo para realizar actividades o usar servicios de baja complejidad (consultar el correo electrónico o visitar webs de periódicos y revistas, mayoritariamente). Los seniors con potencial para comprar por Internet son el 17,5\% que afirma que prefiere no comprar en tienda física o el 58,9\% que afirma tener habilidades o conocimientos para comprar a través de la Red.

Para finalizar este apartado querríamos destacar las principales limitaciones y posibles líneas de investigación futura a partir de este trabajo. La principal limitación es el hecho de usar datos oficiales, ya que aunque facilita el tener una muestra grande de individuos, el investigador no tiene control sobre las variables incluidas ni cómo están medidas. Otra limitación es el hecho haber estudiado únicamente las respuestas de los usuarios de una zona geográfica determinada. En un futuro trabajo podría aplicarse en otros países y analizar la influencia y el papel que puede tener en el proceso de segmentación de mercados la cultura y las características del país.

Finalmente comentar que una futura línea de investigación sería trabajar aspectos teóricos relacionados con los resultados de este trabajo. Por ejemplo, estudiar los factores que conducen a los internautas seniors a ser más activos o más sociales y su relación con el comercio electrónico. También, se debería estudiar los factores que pueden motivar el paso de un segmento a otro. Otra posible línea de investigación, sería la realización de un estudio longitudinal con las mismas variables utilizadas para esta investigación para analizar la evolución y las tendencias del turista senior en cuanto a su comportamiento de compra en línea e introducir la capacidad predictiva como resultado del trabajo.

\section{REFERENCIAS BIBLIOGRÁFICAS}

ABELLÁN A.; PUJOL R. (2016): «Un perfil de las personas mayores en España, 2016: Indicadores estadísticos básicos». Informes Envejecimiento en Red, n 14, pp. 1-22. Disponible en: <http://envejecimiento.csic.es/documentos/documentos/enred-indicadoresbasicos 16.pdf>. [15 de diciembre de 2016]. 
ALÉN, M.E.; DOMÍNGUEZ, T.; FRAÍZ, A. (2010): «El turismo senior como segmento de mercado emergente». Cuadernos de Turismo, n ${ }^{\circ}$ 26, pp. 9-24.

ALÉN, E.; NICOLAU, J.L.; LOSADA, N.; DOMÍNGUEZ, T. (2014): «Determinant factors of senior tourists' length of stay». Annals of Tourism Research, vol. 49, pp. 19-32.

AMARO S.; DUARTE P. (2013): «Online travel purchasing: A literature review». Journal of Travel \& Tourism Marketing, vol. 30, $\mathrm{n}^{\circ}$ 8, pp. 755-785.

BATRA, A. (2009): «Senior pleasure tourists: examination of their demography, travel experience, and travel behavior upon visiting the Bangkok metropolis». International Journal of Hospitality \& Tourism Administration, vol. 10, n 3, pp. 197-212.

BENZECRI, J.P. (1979): «Sur le calcul des taux d'inertie dans l'analyse d'un questionnaire, addendum et erratum». Cahiers de l'Analyse des Données, vol. 4, n 3, pp. 377-378.

BERNE, C., GARCÍA-GONZÁLEZ, M., GARCÍA-UCEDA, M.E.; MÚGICA, J.M. (2015): The effect of ICT on relationship enhancement and performance in tourism channels. Tourism Management, $\mathrm{n}^{\circ}$ 48, pp. 188-198.

BOKSBERGER, P.E.; LAESSER, C. (2009): «Segmentation of the senior travel market by the means of travel motivations». Journal of Vacation Marketing, vol. 15, $\mathrm{n}^{\circ} 4$, pp. 311-322.

CHEN, Y.F.; LAW, R. (2016): «A Review of Research on Electronic Word-of-Mouth in Hospitality and Tourism Management». International Journal of Hospitality \& Tourism Administration, vol. 17, no 4, pp. 347-372.

CHEN, K.H.; LIU, H.H.; CHANG, F.H. (2013): «Essential customer service factors and the segmentation of older visitors within wellness tourism based on hot springs hotels». International Journal of Hospitality Management, vol. 35, pp. 122-132.

CHEN, S.C.; SHOEMAKER, S. (2014): «Age and cohort effects: the American senior tourism market». Annals of Tourism Research, vol. 48, pp. 58-75.

CHEN, C.F.; WU, C.C. (2009): «How motivations, constraints, and demographic factors predict seniors' overseas travel propensity». Asia Pacific Management Review, vol. $14, \mathrm{n}^{\circ} 3$, pp. 301-312.

CHU, A.Z.; CHU, R.J. (2013): «Service willingness and senior tourists: knowledge about aging, attitudes toward the elderly, and work values». The Service Industries Journal, vol. 33, no 12 , pp. 1148-1164.

COOPER, C.; FLETCHER, J.; FYALL, A.; GILBERT, D.; WANHILL, S. (2007): El turismo: teoría y práctica. Madrid: Síntesis.

CRISTÓBAL-FRANSI, E; MARTÍN, E.; DARIES, N. (2015): Behavioral Analysis of Subjects Interacting with Information Technology: categorizing the behavior of e-consumers. International Journal of Services Technology and Management, vol. 21, pp. 163-182.

CRISTÓBAL-FRANSI, E; DARIES, N.; MARTÍN, E. (2013): El turismo y el comercio electrónico en España: un estudio del consumidor y de la empresa turística. Revista de Estudios Turísticos, $\mathrm{n}^{\circ}$ 195, pp. 79-99.

DANN, S. (2007): Branded generations: baby boomers moving into the seniors market». Journal of Product \& Brand Management, vol. 16, nº 6, pp. 429-431. 
DEGERATU, A.M.; RANGASWAMY, A.; WU, J. (2000): «Consumer choice behavior in online and traditional supermarkets: The effects of brand name, price, and other search attributes». International Journal of Research in Marketing, vol. 17, $\mathrm{n}^{\circ}$ 1, pp. 55-78.

DIBB, S.; STERN, P.; WENSLEY, R. (2002): «Marketing knowledge and the value of segmentation». Marketing Intelligence \& Planning, vol. 20, pp. 113-19.

DOLNICAR, S. (2004): "Beyond "Commonsense Segmentation": A Systematics of Segmentation Approaches in Tourism». Journal of Travel Research, vol. 42, n 3, pp. 244-250.

EVERITT, B.S.; LANDAU S.; LEESE M. (2001): Cluster Analysis. London: Arnold.

FLEISCHER, A.; PIZAM, A. (2002): «Tourism constraints among Israeli seniors». Annals of Tourism Research, vol. 29, $\mathrm{n}^{\circ}$ 1, pp. 106-123.

GLOVER, P.; PRIDEAUX, B. (2009): «Implications of population ageing for the development of tourism products and destinations». Journal of Vacation Marketing, vol. $15, \mathrm{n}^{\mathrm{o}} 1$, pp. 25-37.

GONZÁlEZ, A. M.; RODRÍGUEZ, C.; MIRANDA, M.R.; CERVANTES, M. (2009): «Cognitive age as a criterion explaining senior tourists' motivations». International Journal of Culture, Tourism and Hospitality Research,vol. 3, n 2, pp. 148-164.

GONZÁLEZ-RODRIGO, E.: JIMÉNEZ-ZARCO, A.I.; TORRENT J. (2010): Usuarios de Internet y comercio electrónico en Turismo. Actas del VIII Congreso "Turismo y Tecnologías de la Información y las Comunicaciones” TuriTec. Málaga. Pp. 1-17.

HOFFMAN, D.L.; DE LEEUW, J.; ARJUNJI, R.V. (1994): «Multiple correspondence analysis». En BAGOZZI, R.P. (ed.). Advanced Methods of Marketing Research. Oxford: Blackwell, pp. 260-294.

HUNTER-JONES, P.; BLACKBURN, A. (2007): «Understanding the relationship between holiday taking and self-assessed health: An exploratory study of senior tourism». International Journal of Consumer Studies, vol. 31, n ${ }^{\circ}$ 5, pp. 509-516.

INSTITUTO NACIONAL DE ESTADÍSTICA (2016): Indicadores Demográficos Básicos 2016. Madrid. Ministerio de Economía y Competitividad, Disponible en: http://www. ine.es>. [15 de diciembre de 2016].

INSTITUTO NACIONAL DE ESTADÍSTICA (2015a): Indicadores Demográficos Bási$\cos 2015$. Madrid. Ministerio de Economía y Competitividad, Disponible en: http:// www.ine.es $>$. [20 de noviembre de 2016].

INSTITUTO NACIONAL DE ESTADÍSTICA (2015b): Encuesta de Turismo de Residentes (ETR/FAMILITUR). Madrid. Ministerio de Economía y Competitividad, Disponible en: <http://www.ine.es>. [20 de noviembre de 2016].

INSTITUTO NACIONAL DE ESTADÍSTICA. (2015c): TIC-H'15. Encuesta sobre equipamiento y uso de tecnologías de la información y comunicación en los hogares 2015. Informe metodológico. Madrid. Ministerio de Economía y Competitividad, Disponible en: <http://www.ine.es/metodologia/t25/t25304506615.pdf> [10 de noviembre de 2016].

JANG, S.; HAM, S. (2009): «A double-hurdle analysis of travel expenditure: baby boomers seniors versus older seniors». Tourism Management, vol. 30, pp. 372-380.

JANG, S.; WU, C.M.E. (2006): «Seniors' travel motivation and the influential factors: An examination of Taiwanese seniors». Tourism Management, vol. 27, n ${ }^{\circ}$, pp. 306-316. 
JANG, S.; BAI, B.; HU, C.; WU, C.M.E. (2009): «Affect, travel motivation, and travel intention: A senior market». Journal of Hospitality \& Tourism Research, vol. 33, $\mathrm{n}^{\circ}$ 1, pp. 51-73.

KAZEMINIA, A.; DEL CHIAPPA, G.; JAFARI, J. (2015): «Seniors» travel constraints and their coping strategies». Journal of Travel Research, vol. 54, n 1, pp. 80-93.

KIM, H.; FESENMAIER, D.R. (2008): «Persuasive Design of Destination Web Sites: An Analysis of First Impression». Journal of Travel Research, vol. 47, pp. 3-13.

KIM, M.J.; LEE, C.K.; BONN, M. (2016): «The effect of social capital and altruism on seniors' revisit intention to social network sites for tourism-related purposes». Tourism Management, vol. 53, pp. 96-107.

KUO, H.I.; LU, C.L. (2013): «Expenditure-based segmentation: application of quantile regression to analyse the travel expenditures of baby boomer house- holds». Tourism Economics, vol. 19, n 6, pp. 1429-1441.

LAMBERT-PANDRAUD, R.; LAURENT, G.; LAPERSONNE, E. (2005): «Repeat purchasing of new automobiles by older consumers: empirical evidence and interpretations». Journal of Marketing, vol. 69, n 2, pp. 97-113.

LE ROUX, B.; ROUANET, H. (2010): Multiple Correspondence Analysis. Thousand Oaks: Sage.

LE SERRE, D.; LEGOHÉREL, P.; WEBER, K. (2013): «Seniors' motivations and perceived risks: A cross-cultural study». Journal of International Consumer Marketing, vol. 25, n ${ }^{\circ} 2$, pp. 61-79.

LOHMANN, M.; DANIELSSON, J. (2001): «Predicting travel patterns of senior citizens: how the past may provide a key to the future». Journal of Vacation Marketing, vol. 7, n $\mathrm{n}^{\mathrm{O}}$ 4, pp. 357-366.

LOSADA, M.N.; ALÉN, E.; DOMÍNGUEZ, T. (2015): «Análisis de los determinantes de la decisión de viajar de los senior españoles». Estudios y Perspectivas en Turismo, vol. 24, n ${ }^{\circ} 1$, pp. 1-20.

LOSADA, M.N.; ALÉN, E.; DOMÍNGUEZ, T.; NICOLAU, J.L. (2016): «Travel frequency of seniors tourists». Tourism Management, vol. 53, pp. 88-95.

MAHADEVAN, R. (2014): «Understanding senior self-drive tourism in Australia using a contingency behavior model». Journal of Travel Research, vol. 53, n 2, pp. 252-259.

MORGAN, N.; PRITCHARD, A.; SEDGLEY, D. (2015): «Social tourism and well-being in later life». Annals of Tourism Research, vol. 52, pp. 1-15.

MOUTINHO, L.; BALLANTYNE, R.; RATE, S. (2011): «The new business environment and trends in tourism». En: MOUTINHO, L. (ed.). Strategic management in tourism. Oxfordshire: CAB International, pp. 1-19.

NIELSEN, K. (2014): «Approaches to seniors' tourist behaviour». Tourism Review, vol. 69, $\mathrm{n}^{\circ} 2$, pp. 111-121.

NUSAIR, K. K.; BILGIHAN, A.; OKUMUS, F. (2012): «The role of online social network travel websites in creating social interaction for Gen Y travelers». International Journal of Tourism Research, vol. 15, no 5, pp. 458-472.

NYAUPANE, G.P.; MCCABE, J.T.; ANDERECK, K.L. (2008): «Seniors' travel constraints: stepwise logistic regression analysis». Tourism Analysis, vol. 13, n 4, pp. 341-354. 
OBSERVATORIO NACIONAL DE LAS TELECOMUNICACIONES Y DE LA SOCIEDAD DE LA INFORMACIÓN (2015 ): Estudio sobre Comercio Electrónico B2C 2014: Edición 2015. Madrid: Ministerio de Industria, Energía y Turismo. Disponible en: <http://www.ontsi.red.es/onsti/>. [11 de octubre de 2016].

OBSERVATORIO NACIONAL DE LAS TELECOMUNICACIONES Y DE LA SOCIEDAD DE LA INFORMACIÓN (2015b): Perfil sociodemográfico de los internautas. Madrid. Ministerio de Industria, Energía y Turismo. Disponible en: <http://www.ontsi. red.es/ontsi/>. [21 de diciembre de 2015].

OPPERMANN, M. (1995): «Travel life cycle». Annals of Tourism Research, vol. 22, $\mathrm{n}^{\circ}$ 3, pp. 535-552.

ORTEGA F. J.; RÍOS M.A.; RUIZ-JIMÉNEZ A.; CEBALLOS C. (2012): Cómo actuar de manera eficiente en la comercialización online del sector hotelero andaluz. Actas $V$ Jornadas de Investigación en Turismo: Turismo y Sostenibilidad. Sevilla. pp. 515-540.

PATTERSON, I.R. (2006): Growing older. Tourism and leisure behaviour of older adults. Cambridge: CABI.

PERAL, B; GAITÁN, J.; ARENAS R.; JERÓNIMO, M. A. (2013): «El papel de las variables sociodemográficas en el uso de las aplicaciones basadas en Internet por los Mayores». Revista Innovar. Revista de Ciencias Administrativas y Sociales, vol. 23, $\mathrm{n}^{\mathrm{o}}$ 48, pp. 55-65.

PERAL, B.; RODRÍGUEZ-BOBADA, J.; SÁNCHEZ, M.J.; VILLAREJO, A.F. (2011): «La elección de servicios turísticos online por los usuarios mayores de 55 años. Segmentación mediante clases latentes». Actas del congreso XXIII Congreso Nacional de Marketing de AEMARK. Castellón: ESIC.

PESONEN, J.; KOMPPULA, R.; RIIHINEN, A. (2015): «Typology of senior travellers as users of tourism information technology». Information Technology \& Tourism, vol. $15, n^{\circ} 3$, pp. 233-252.

RAMOS, C.M.; RODRIGUES, P.M.; RODRIGUES, J.M. (2015): «Opportunities, Emerging Features, and Trends in Electronic Distribution in Tourism». International Journal of Information Systems and Social Change (IJISSC), vol. 6, $\mathrm{n}^{\circ}$ 4, pp. 17-32.

RICHTER, F. (2013): U.S. seniors warm up to social networking. Nueva York; Statista. Disponible en: <http://www.statista.com/chart/1347/social-network-usage-in-the-us/>. [30 de abril de 2016].

SCHRÖDER, A.; WIDMANN, T. (2007): «Demographic change and its impact on the travel industry: Oldies-nothing but goldies?». En: CONRADY, R. y BUCK, M. (eds.). Trends and issues in Global Tourism. Berlin: Springer, pp. 3-17.

SHIM, S.; GEHRT, K.C.; SIEK, M. (2005): «Attitude and Behavior Regarding Pleasure Travel among Mature Consumers: A Socialization Perspective». Journal of Travel \& Tourism Marketing, vol. 18, $\mathrm{n}^{\circ}$ 2, pp. 69-81.

SWINYARD, W.R.; SMITH, S.M. (2003): «Why people (don't) shop online: a lifestyle study of the Internet consumer». Psychology \& Marketing, vol. 20, n 7, pp. 567-97.

THÉBAULT, M.; PICARD, P.; OUEDRAOGO, A. (2013): «Seniors and tourism: An international exploratory study on the use of the internet for researching recreational information use». International Business Research, vol. 6, n 3, pp. 22-28. 
TRÉGUER, J.P.; SÉGATI, J.M. (2005): Les nouveaux marketings - Marketing générationnel, Gay marketing, Marketing ethnique. Paris: Dunod.

VAN DEN BERG, P.; ARENTZE, T.; TIMMERMANS, H. (2011): «Estimating social travel demand of senior citizens in the Netherlands». Journal of Transport Geography, vol. 19, pp. 323-331.

VIGOLO, V.; CONFENTE, I. (2013): «Older tourists: An exploratory study on online behaviour». En: XIANG, Z.; TUSSYADIAH, L. (eds.). Information and Сотmunication Technologies in Tourism 2014. Lugano: Springer International Publishing Switzerland, pp. 439-452.

VILLAREJO, Á.F.; RONDÁN, F.J.; REVILLA, M.Á. (2016): «Tipología de compradores online mayores de 55 años». Revista Innovar. Revista de Ciencias Administrativas y Sociales, vol. 26, ${ }^{\circ}$ 59, pp. 61-72.

WANG, K.C.; MA, A.P.; HSU, M.T.; JAO, P.C.; LIN, C.W. (2013): «Seniors' perceptions of service features on outbound group package tours». Journal of Business Research, vol. $66, \mathrm{n}^{\circ} 8$, pp. 1021-1027.

WARD, A. (2014): «Segmenting the senior tourism market in Ireland based on travel motivations». Journal of Vacation Marketing, vol. 20, $\mathrm{n}^{\circ}$ 3, pp. 267-277.

WEN, I. (2012): «An empirical study of an online travel purchase intention model». Journal of Travel \& Tourism Marketing, vol. 29, $\mathrm{n}^{\circ}$ 1, pp. 18-39.

ZHENG, L.; FAVIER, M.; HUANG, P.; COAT, F. (2012): «Chinese consumer perceived risk and risk relievers in e-shopping for clothing». Journal of Electronic Commerce Research, vol. 13, no 3, pp. 255-274.

ZIMMER, Z.; BRAYLEY, R.E.; SEARLE, M.S. (1995): «Whether to go and where to go: identification of important influences on seniors' decisions to travel». Journal of Travel Research, vol. 33, $\mathrm{n}^{\circ}$ 3, pp. 3-10. 
